\title{
Clinical setting influences physiological responses in dental implant patients
}

\author{
Milene Cardoso Candido ${ }^{1}$, Roberto Andreatini ${ }^{2}$, João Cesar Zielak ${ }^{1}$, \\ Juliana Feltrin Souza ${ }^{1}$, Estela Maris Losso ${ }^{1}$
}

\author{
${ }^{1}$ Universidade Positivo - UP, School of Dentistry, Area of Implantology, Curitiba, PR, Brazil \\ 2 Universidade Federal do Paraná - UFPR, Department of Pharmacology, Area of Biological Sciences, Curitiba, PR, Brazil
}

Received for publication: April 23, 2014 Accepted: June 03, 2014

Correspondence to: Estela Maris Losso

Universidade Positivo - Curso de Odontologia Rua Pedro Viriato Parigot de Souza, 5300

Campo Comprido

CEP: 81280-330, Curitiba, PR, Brasil Phone: +55 4133173456 Fax: +55 4133365962

Email: lossoem@gmail.com

\begin{abstract}
Anxiety is often observed in dental procedures and may cause promote alteration in the physiological responses during implant surgeries. Aim: To evaluate changes in blood pressure and heart rate in patients undergoing dental implant procedures, considering the dental setting as the main variable. Methods: Fifty-five patients who underwent dental implant surgery were evaluated. Thirty-seven were treated at a university clinic and 18 were treated at a private office. Blood pressure and heart rate were measured at the following time-points: at the appointment prior to surgery (T0), immediately before the surgical procedure (T1), during anesthesia (T2), during implant installation (T3), immediately after the surgical procedure (T4) and at the first follow-up appointment after surgery (T5). The data were analyzed by two-way analysis of variance and Student's t-test. Results: The university clinic patients had an increase in heart rate at $\mathrm{T5}\left(\mathrm{t}_{53}=2.62\right.$, $p<0.05)$ compared with private office patients. Systolic blood pressure in university clinic patients was higher at T2 $\left(t_{53}=2.86, p<0.01\right)$, T3 $\left(t_{53}=2.64, p<0.05\right)$, and T4 $\left(t_{53}=3.15, p<0.01\right)$. Diastolic blood pressure at T2 $\left(t_{53}=3.15, p<0.01\right)$ and $T 3\left(t_{53}=3.86, p<0.01\right)$ were also higher in university clinic patients. Conclusions: These results suggest that the dental setting is a relevant factor when planning dental implant surgery.
\end{abstract}

Keywords: dental implants; blood pressure; heart rate.

\section{Introduction}

Anxiety is a phenomenon characterized by subjective feelings of tension, apprehension, nervousness and preoccupation that may be experienced when an individual contacts an aggressor, such as dental surgery ${ }^{1-4}$. Anxiety is a consciously perceived emotional reaction that intensifies the activity of the autonomic nervous system. The sympathetic nervous system acts directly on the adrenal gland to promote epinephrine and norepinephrine release. Activation of this system produces responses that include changes in heart rate (HR), breathing, and blood pressure (BP) patterns, and restlessness, tremors and increased sweating ${ }^{1,5-7}$. Blood pressure and HR can be altered in dental procedures ${ }^{8}$. Beck and Weaver ${ }^{9}$ (1981) studied BP and HR in nonstressful and stressful (dental surgery) procedures. They reported that systolic and diastolic BP did not vary on the day of surgery. However, HR varied in all phases of the treatment, with a higher variation on the day of surgery. The authors also suggested that the pretreatment period appears not to influence significantly the BP in healthy adults, with no gender differences.

Liau et al. ${ }^{10}$ (2008) analyzed dental anxiety (Corah's Dental Anxiety) in 180 patients who underwent tooth extraction under local anesthesia in the mandible 
and reported anxiety with cardiovascular alterations. The treatment occurred in a university hospital. The anxiety scale was applied before anesthesia, and cardiovascular parameters (i.e., BP, HR, oxygen saturation and electrocardiography) were measured every $5 \mathrm{~min}$ up to $15 \mathrm{~min}$ after anesthesia. The highest alterations in HR occurred during the induction of anesthesia in individuals who were more anxious, in patients who reported a traumatic history with dental treatment and in patients who reported pain during the induction of anesthesia. Patients with pain had increased systolic BP, but no differences were found in diastolic BP.

Bispo et al. ${ }^{8}$ (2011) also studied BP and HR in adult patients in different phases of root canal filling in molar teeth (Class I) using different anesthetic drugs. They reported that the cardiovascular alterations were similar among the different anesthetic drugs, but the cardiovascular parameters were influenced by the phase of the dental treatment. The cardiovascular parameters were higher before the beginning of treatment and before local anesthesia, during the test of pulp vitality after anesthesia, during the procedure itself and at the end of treatment. It may be assumed that anxiety had an effect on these cardiovascular parameters during the root filling treatment.

To the best of our knowledge, there are no studies assessing the influence of the clinical environment on cardiovascular responses to dental procedures. Considering the importance of cardiovascular function in surgical trauma ${ }^{11}$, the objective of the present study was to evaluate BP and HR in two different dental settings in patients who underwent dental implant surgery or a related procedure.

\section{Material and methods}

This was a prospective study (implant surgeries) in which physiological alterations in BP and HR were evaluated in patients treated at the Positivo University Surgical Center and at a private clinic, both in city of Curitiba, PR, Brazil. Approval was obtained from the Ethics Committee of Positivo University (075/10).

The participants were 55 patients of both genders ( 45 women, $75 \%$ ) aged 30 to 69 years who sought dental implant treatment. Thirty-seven were treated at Positivo University Surgical Center (university clinic [UC] group) and 18 at a private dental office (private office [PO] group). The inclusion criteria were: literate patient with good general health, not using any drug that could produce cardiovascular alterations. The criteria for exclusion were the following: patients with syndromes, systemic disease, cardiac problems and use of drugs that produce cardiovascular alterations. The patients were evaluated during three different phases of treatment, according to the following schedule:

- Consultation before surgery (T0). The consultation before surgery occurred between 7 and 21 days before the procedure. At this time, the patients were identified by recording their date of birth, gender and medical history (overall health and use of medications). Blood pressure and HR were recorded.
- Day of the procedure (T1, T2, T3, and T4). During the consultation on the day of dental implant, the systolic and diastolic BP and HR were measured immediately before the surgical procedure in the waiting room (T1). In the procedure room, BP and HR were measured at the moment of anesthesia induction (T2), during the procedure when the dental implant motor was used (T3) and immediately after surgery (T4).

- Postsurgery consultation (T5). During the first followup visit for suture removal, between 7 and 10 days after surgery systolic and diastolic BP and HR were measured again.

\section{Surgery and Cardiovascular parameters}

In order to obtain the cardiovascular parameters, a properly calibrated noninvasive semiautomatic digital BP monitor (Model MF-621 SE; More Fitness, São Paulo, SP, Brazil) was used to measure systolic and diastolic BP and HR simultaneously. The patients received the following instructions: to empty the bladder, not to exercise, not to ingest coffee or alcoholic beverages and not to eat in excess or smoke cigarettes within the $30 \mathrm{~min}$ prior to the evaluation. The patients received an explanation about the measurement procedure that was performed while sitting and were asked to rest for 5-10 min. The brachial artery was located by palpation, and the cuff was firmly positioned, with the rubber bag centered over the brachial artery. The patient's arm was positioned at heart level, and the patient was asked not to speak during the measurement procedure. The data were recorded on the patient's chart. In case of equipment error, new measurements were performed after 1-2 min.

The cardiovascular parameter measurements and surgeries were performed in both locations by the same properly trained team. For the surgeries, the procedures were performed using the same technique in all patients. In the procedures that involved surgery anesthesia was performed used with $4 \%$ articaine chloride and epinephrine $(1: 100,000)$, or $2 \%$ mepivacaine chloride with epinephrine $(1: 100,000)$. The amount varied according to the need for surgery and did not exceed the maximal recommended dose.

During the postoperative period, ibuprofen was used for analgesia. Amoxicillin $(500 \mathrm{mg}$ ) was administered every $8 \mathrm{~h}$, or clindamycin $(600 \mathrm{mg})$ was administered every $6 \mathrm{~h}$ for 7 days.

\section{Statistical analysis}

The data were analyzed statistically using one- or twoway analysis of variance (ANOVA), depending on the conditions. Individual comparisons were performed using Student's t-test or Duncan's test for multiple comparisons. For all tests, the significance level was set to $5 \%$.

\section{Results}

Figure 1 presents the BP results for groups UC and PO. The ANOVA revealed a significant effect of group on systolic BP $\left(\mathrm{F}_{5.270}=5.81, \mathrm{p}<0.001\right)$. Systolic BP at T4 (i.e., the end of surgery) was significantly higher compared with the other time-points $(\mathrm{p}<0.01)$, except for T1 $(\mathrm{p}>0.05)$. Systolic BP 


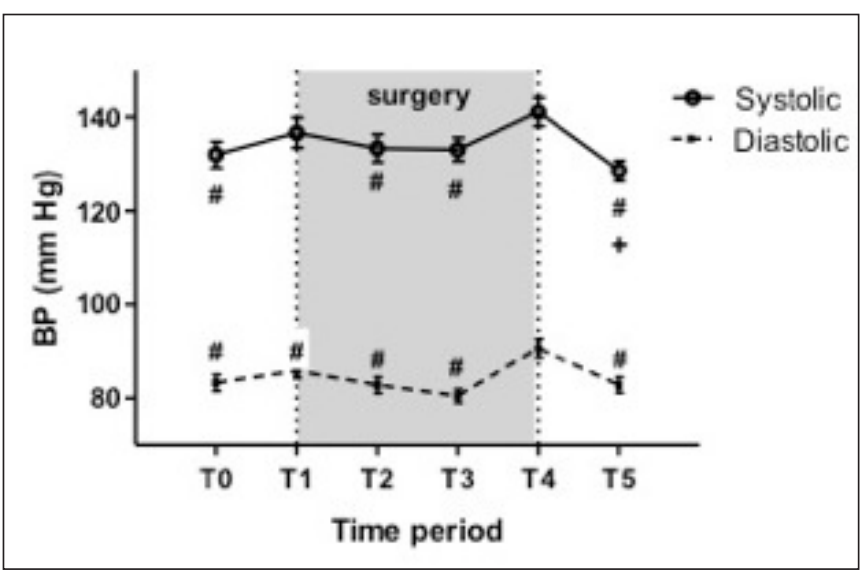

Fig. 1. Systolic and diastolic blood pressure (BP) in the UC and PO groups. The data are expressed as mean + standard error $(n=55)$. ${ }^{*} p<0.05$, compared with $T 4$; ${ }^{+} \mathrm{p}<0.05$, compared with $\mathrm{T} 1$.

at T5 was lower than at T4 $(\mathrm{p}<0.01)$. Diastolic BP was significantly higher at $\mathrm{T} 4$ compared with the other evaluations $\left(\mathrm{F}_{5,270}=9.58, \mathrm{p}<0.001\right)$, which did not differ from each other.

Analyzing the systolic BP (Figure 2) as a function of treatment setting, ANOVA revealed significant effects of setting $\left(\mathrm{F}_{1,53}=7.53, \mathrm{p}<0.01\right)$ and time $\left(\mathrm{F}_{5,265}=3.97, \mathrm{p}<0.01\right)$ but no interaction between these factors $\left(\mathrm{F}_{5,265}=1.69\right.$, $\mathrm{p}>0.05)$. Statistically significant differences were found between the UC and PO groups at T2 $\left(\mathrm{t}_{53}=2.86, \mathrm{p}<0.01\right)$, $\mathrm{T} 3\left(\mathrm{t}_{53}=2.64, \mathrm{p}<0.05\right)$, and $\mathrm{T} 4\left(\mathrm{t}_{53}=3.15, \mathrm{p}<0.01\right.$; Fig. 2$)$. The intra-group analysis revealed statistically significant differences in systolic BP in the UC group $\left(\mathrm{F}_{5,180}=5.53, \mathrm{p}<\right.$ 0.01 ), with an increase at T4 compared with the other timepoints $(\mathrm{p}<0.05)$. However, systolic BP at T5 was lower than at T2 and T4 $(\mathrm{p}<0.05)$. In the PO group, no statistically significant differences were found in systolic BP $\left(\mathrm{F}_{5.180}=1.67\right.$, $p>0.05$ ) at any of the time-points.

The analyses of diastolic BP as a function of treatment setting (UC and PO groups) revealed significant effects of setting $\left(\mathrm{F}_{1.53}=8.33, \mathrm{p}<0.01\right)$ and time $\left(\mathrm{F}_{5.265}=9.48, \mathrm{p}<0.01\right)$ but no interaction between these factors $\left(\mathrm{F}_{5.265}=0.87\right.$, $\mathrm{p}>0.05)$. Statistically significant differences were found between the UC and PO groups at T2 $\left(\mathrm{t}_{53}=3.15, \mathrm{p}<0.01\right)$ and T3 $\left(\mathrm{t}_{53}=3.86, \mathrm{p}<0.01\right.$; Fig. 2$)$. The intra-group analyses revealed a significant effect of group on diastolic BP $\left(\mathrm{F}_{5.180}=4.70, \mathrm{p}<0.01\right)$, with an increase at $\mathrm{T} 4$ compared with the other time-points $(\mathrm{p}<0.05)$. Statistically significant differences in diastolic BP were also found in the PO group $\left(\mathrm{F}_{5.180}=7.08, \mathrm{p}<0.01\right)$, with an increase at $\mathrm{T} 4$ compared with the other time-points $(\mathrm{p}<0.05)$, except for T1. Additionally, a reduction of diastolic BP was observed at $\mathrm{T} 3$ compared with the other time-points $(\mathrm{p}<0.05)$, except for $\mathrm{T} 3$.

The comparison of HR between the UC and PO groups (Fig. 3) revealed a statistically significant effect of time $\left(\mathrm{F}_{5.265}=2.99, \mathrm{p}<0.01\right)$ and a statistically significant time ' setting interaction $\left(\mathrm{F}_{5.265}=3.01, \mathrm{p}<0.05\right)$, but no effect of setting was found $\left(\mathrm{F}_{1,53}=0.86, \mathrm{p}>0.05\right)$. The only difference observed between the UC and PO groups was a reduction of $\mathrm{HR}$ at $\mathrm{T} 5$ in the PO group $\left(\mathrm{t}_{53}=2.62, \mathrm{p}<0.05\right)$. No statistically

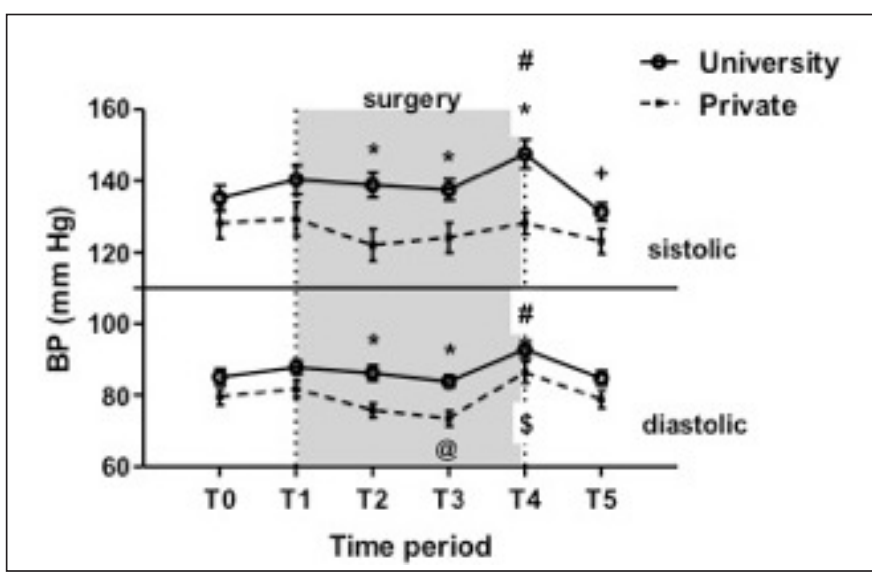

Fig. 2. Systolic and diastolic blood pressure (BP) in dental implant patients in the UC group ( $n=37)$ and PO group ( $n=18)$. The data are expressed as mean + standard error. ${ }^{*} p<0.05$, compared with PO group at the same time-point; ${ }^{*} p<0.05$, compared with all other time-points in the same group; ${ }^{+} p<0.05$, T2 vs. T4 in the same group; ${ }^{\$} p<0.05$, compared with T0, T2, T3 and T5 in the same group; ${ }_{\mathrm{Q}} \mathrm{p}<0.05$, compared with $\mathrm{T} 0, \mathrm{~T} 1, \mathrm{~T} 4$ and $\mathrm{T} 5$ in the same group.

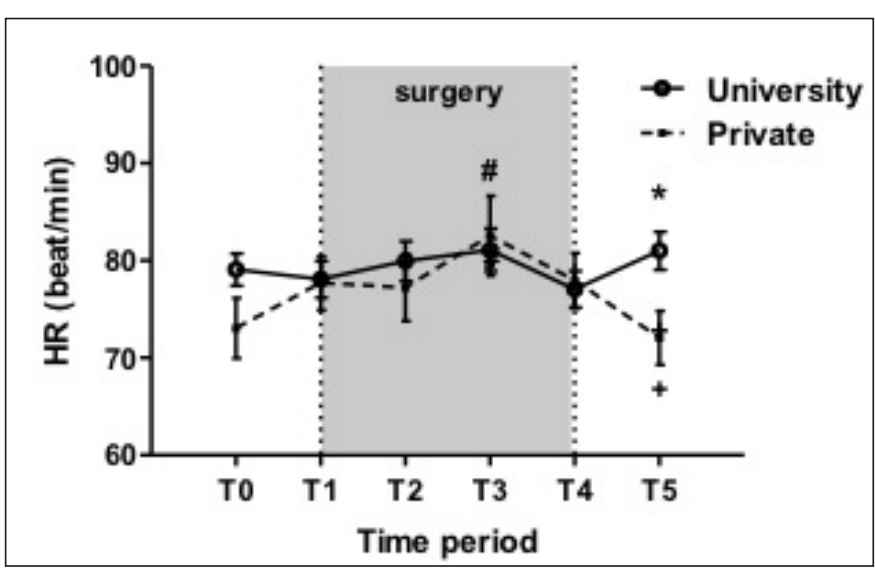

Fig. 3. Heart rate (HR) in dental implant patients of the UC and PO groups. ${ }^{*} p<0.05$, compared with PO group; $\# p<0.05$, compared with T0, T2, T4 and T5 in the same group; ${ }^{+} p<0.05$, compared with $\mathrm{T} 1, \mathrm{~T} 2, \mathrm{~T} 3$ and $\mathrm{T} 4$ in the same group.

significant differences were found for the other comparisons $(t<1.88, p>0.05)$. The intra-group analysis showed that HR did not differ in the UC group $\left(\mathrm{F}_{5.180}=1.24, \mathrm{p}>0.05\right)$. Statistically significant differences in HR were found in the PO group $\left(\mathrm{F}_{5.85}=5.41, \mathrm{p}<0.01\right)$, with an increase at $\mathrm{T} 3$ compared with the other time-points (all $\mathrm{p}<0.05$ ), except for T1. A reduction of HR was also observed at T5 compared with the other time-points $(\mathrm{p}<0.05)$, except for T0.

\section{Discussion}

The main result of the present study was that the treatment setting was sufficient to produce changes in the $\mathrm{BP}$ of patients who underwent dental implant procedures. The patients who were treated in the private clinic had lower BP during all phases of the study, but mainly during anesthesia, use of the dental implant motor and at the end of surgery. The clinical environment might have caused such changes because several surgical procedures are performed simultaneously at the university surgical center, with various 
noise stimuli, such as high-speed rotary instruments and saliva suction devices. The use of a dental implant motor is a stressful factor that can alter BP. On the other hand, treatment in the private clinic occurs individually with fewer noise stimuli. The average systolic and diastolic BP had higher peaks at the end of the surgery, regardless of the treatment setting. This effect may be attributed to the fact that the patients were beginning to feel pain and were tired, and this could be related to an increase in anxiety and hemodynamic changes ${ }^{2,6,12-13}$

These findings are partially consistent with the results of Beck and Weaver9 (1981), who did not report variations in BP during some phases of dental treatment, but reported an increase in BP at more stressful moments (i.e., during the surgical procedure and use of the dental implant motor) in the same way as in the present study. The location where the surgical procedures were performed (i.e., university surgical center or private clinic) was not mentioned in their paper. Liau et al. ${ }^{10}$ (2008) reported greater alterations in HR during anesthesia induction in more anxious individuals and increased systolic BP in patients who reported pain, with no differences in diastolic BP. In that study, the treatment occurred in a university setting.

The noise of the dental implant motor is a stressful agent that can explain the maximal peak HR during its use in the treatment both at the university and private clinic settings ${ }^{14-16}$. Beck and Weaver ${ }^{9}$ (1981), Liau et al. ${ }^{10}$ (2008) and Bispo et al. ${ }^{8}$ (2011) reported that changes in HR occurred in more anxious individuals, suggesting a relationship between stress during dental treatment and HR. Eli et al. ${ }^{17}$ (2008) observed that increased anxiety and the expectation of feeling pain had profound effects on patients capacity to recognize information during dental procedures, causing difficulties in processing information that was provided before and during the dental procedure.

Although the surgeries were performed at both locations by the same properly trained team, the university environment could be considered a more stressful agent. Although no scientific evidence is presented herein, it can be ascertained that this occurrence may be associated with a possible collective sense existing among patients subjected to procedures performed by professionals undergoing training programs, who could be have less experience and skills than what is normally expected at private clinics.

As a health professional, the dentist should not limit its role to the dental treatment itself. Dentists should also be prepared to identify physiological alterations in their patients and investigate their possible sources. Hence, the evocation of fear could be avoided, improving cardiovascular alterations.

Unfortunately, the observation and identification of behavioral changes are not easy tasks for the dental clinician, whose training seldom includes behavioral observations or knowledge about behavior management. Technical acumen is a product of a teaching system in which manual skills and technological procedures are taught and enhanced, many times contrasting with the need for a more humane approach, which often is required when considering the physical proximity between the patient and dentist, and the emotional vulnerability of many people ${ }^{6}$. Further studies are required to identify the factors in the treatment environment that can increase physiological changes or reduce anxiety (e.g., the use of lavender or orange essence in the waiting room) $)^{18-20}$.

It may be concluded that the clinical setting is an important factor when planning dental surgeries. Moreover, identifying the characteristics of the environment that negatively influence physiological responses in dental implant patients is necessary to reduce risk, especially at places with high attendance rates, such as university clinics.

\section{References}

1. Spielberg C, Gorgush R, Lushene R. Manual for the strait-trait anxiety inventory. Palo Alto, CA: Consulting Psycologists Press; 1970.

2. Muglali M, Komerik N. Factors related to patients' anxiety before and after oral surgery. J Oral Maxillofac Sur. 2008; 66: 870-7.

3. Kim S, Lee YJ, Lee S, Moon HS, Chung MK. Assessment of pain and anxiety following surgical placement of dental implants. Int J Oral Maxillofacial Implants. 2013; 28: 531-5.

4. Humphris G, Crawford JR, Hill K, Gilbert A, Freeman R. UK population norms for the modified dental anxiety scale with percentile calculator: adult dental health survey 2009 results. BMC Oral Health. 2013; 13: 29.

5. Hall JE. Guyton and Hall textbook of medical physiology: Enhanced Ebook: Elsevier Health Sciences; 2010.

6. Sanikop S, Agrawal P, Patil S. Relationship between dental anxiety and pain perception during scaling. J Oral Sci. 2011; 53: 341-8.

7. Romano MM, Soares MS, Pastore CA, Tornelli MJ, de Oliveira Guare R, Adde CA. A study of effectiveness of midazolam sedation for prevention of myocardial arrhythmias in endosseous implant placement. Clin Oral Implants Res. 2012; 23: 489-95.

8. Bispo CG, Tortamano IP, Rocha RG, Francischone CE, Borsatti MA, da Silva JC Jr, et al. Cardiovascular responses to different stages of restorative dental treatment unaffected by local anaesthetic type. Aust Dent J. 2011; 56 : 312-6.

9. BeckFM, Weaver JM. Blood pressure and heart rate responses to anticipated high-stress dental treatment. J Dent Res. 1981; 60: 26-9.

10. Liau FL, Kok SH, Lee JJ, Kuo RC, Hwang CR, Yang PJ, et al. Cardiovascular influence of dental anxiety during local anesthesia for tooth extraction. Oral Sur Oral Med Oral Pathol Oral Radiol Endond. 2008; 105: 16-26.

11. Desborough JP. The stress response to trauma and surgery. Br JAnaesth. 2000; 85: 109-17.

12. Eli I, Schwartz-Arad D, Baht R, Ben-Tuvim H. Effect of anxiety on the experience of pain in implant insertion. Clin Oral Implants Res. 2003; 14: $115-8$.

13. Vassend O, Roysamb E, Nielsen CS. Dental anxiety in relation to neuroticism and pain sensitivity. A twin study. J Anxiety Disord. 2011; 25: 302-8.

14. Corah NL. Development of a dental anxiety scale. J Dent Res. 1969; 48 : 596.

15. Oosterink FM, de Jongh A, Aartman IH. What are people afraid of during dental treatment? Anxiety-provoking capacity of 67 stimuli characteristic of the dental setting. Eur J Oral Sci. 2008; 116: 44-51.

16. 16Malamed SF. Knowing your patients. JAm Dent Assoc. 2010; 141(Suppl 1): $3 S-7 S$

17. Eli I, Schwartz-Arad D, Bartal Y. Anxiety and ability to recognize clinical information in dentistry. J Dent Res. 2008; 87: 65-8.

18. Lehrner J, Marwinski G, Lehr S, Johren P, Deecke L. Ambient odors of orange and lavender reduce anxiety and improve mood in a dental office. Physiol Behav. 2005; 86: 92-5. 
19. Lehrner J, Eckersberger C, Walla P, Potsch G, Deecke L. Ambient odor of orange in a dental office reduces anxiety and improves mood in female patients. Physiol Behav. 2000; 71: 83-6.

20. Kritsidima M, Newton T, Asimakopoulou K. The effects of lavender scent on dental patient anxiety levels: a cluster randomised-controlled trial. Community Dent and Oral Epidemiol. 2010; 38: 83-7. 